positivity among this population also demonstrated variance across geographic regions ranging from $13.2 \%$ (Aberdeen) to $4.6 \%$ (California). Among $>26$-year-old women, similar levels of screening were seen ranging from 34.4\% (Alaska) and 5.7\% (Bemidji); however, significantly less positivity was identified $(1.4 \%-5.6 \%)$ (Abstract P5-S7.10 table 1).

Abstract P5-S7.10 Table 1 Chlamydia screening coverage among Al/ AN women $(\leq 25 \& \geq 26)$ by geographic regions, Stop Chlamydia Project-2009

\begin{tabular}{|c|c|c|c|c|c|}
\hline Geographic Regions & \# of Tests & $\leq 25$ & $\%$ Positive & $\geq 26$ & $\%$ Positive \\
\hline Aberdeen (IA, NE, NS, SD) & 8590 & $31.70 \%$ & $13.20 \%$ & $19.00 \%$ & $3.80 \%$ \\
\hline Alaska (AK) & 12185 & $50.80 \%$ & $8.60 \%$ & $34.40 \%$ & $2.50 \%$ \\
\hline Bemidji (MI, MN, WI) & 190 & $10.90 \%$ & $5.00 \%$ & $5.70 \%$ & $5.60 \%$ \\
\hline Billings (MT, WY) & 2630 & $28.70 \%$ & $9.20 \%$ & $18.70 \%$ & $1.40 \%$ \\
\hline California (CA) & 173 & $6.80 \%$ & $4.60 \%$ & $6.10 \%$ & $1.90 \%$ \\
\hline Oklahoma (KS, OK) & 2211 & $14.70 \%$ & $11.60 \%$ & $10.90 \%$ & $2.80 \%$ \\
\hline Portland (ID, OR, WA) & 2063 & $28.80 \%$ & $9.20 \%$ & $23.80 \%$ & $2.40 \%$ \\
\hline $\begin{array}{l}\text { Southwest (AZ, CO, NM, } \\
\text { NV, TX, UT) }\end{array}$ & 15506 & $29.30 \%$ & $9.40 \%$ & $27.70 \%$ & $4.00 \%$ \\
\hline $\begin{array}{l}\text { Nashville (AL, AR, CT, } \\
\text { DE, FL, GA, IL, IN, KY, } \\
\text { LA, MA, MD, ME, MO, MS, } \\
\text { NC, NH, NJ, NY, OH, PA, } \\
\text { RI, SC, TN, VA, VT, WV) }\end{array}$ & \multicolumn{5}{|c|}{ No participating sites } \\
\hline Overall Total & 43548 & $31.50 \%$ & $10.00 \%$ & $23.80 \%$ & $3.30 \%$ \\
\hline
\end{tabular}

Conclusions This is the first time screening coverage for American Indian/Alaska Native women has been evaluated by geographic regions. These data can help inform program improvement activities to maximise screening outcomes by expanding testing among women $<25$ years old and limiting routine screening efforts in older women ( $>26$ years old) in order to better utilise testing resources to expand coverage among those at greatest risk for chlamydia ( $<25$ years old).

\section{P5-S7.11 CHLAMYDIA AND GONORRHOEA POSITIVITY AMONG FEMALES AGED 15-25 YEARS TESTED IN COMMUNITY HEALTH CENTERS IN 12 COUNTIES IN CY2009, REGION II INFERTILITY PREVENTION PROJECT, USA}

doi:10.1136/sextrans-2011-050108.606

K Opdyke, M Nelson, D Middleton. Cicatelli Associates Inc., New York, USA

Background The US Centers for Disease Control and Prevention (CDC) recommends annual chlamydia screening for sexually active females aged $<26$ years. Community health centers (CHCs) have been a focal point for Health Care Reform in the US and have traditionally served as safety-net providers, however little is known about CT screening practices in CHCs or CT prevalence among $\mathrm{CHC}$ clients. The Region II Infertility Prevention Project (IPP) supports chlamydia and gonorrhoea (CT/GC) prevalence monitoring in participating facilities throughout New Jersey, New York, Puerto Rico and the US Virgin Islands, including a small number of CHCs.

Methods We reviewed Region II IPP CT/GC prevalence monitoring data for females aged 15-25 years tested in CY2009 attending CHCs for non-prenatal visits by age, test result, and laboratory test type, and compared with data for females attending family planning (FP) clinics for non-prenatal visits in the same counties. A total of $3103 \mathrm{CT}$ and 2890 GC test records were associated with $18 \mathrm{CHCs}$ in 12 counties in New Jersey, New York, and the US Virgin Islands; 35 FP clinics in the same counties reported 32905 CT and 19882 GC tests. Results CT positivity among females aged 15-19 and 20-25 years in CHCs was $11.4 \%(n=640)$ and $5.7 \%(n=2463)$, respectively, compared with $8.5 \%(n=10946)$ and $4.6 \%(n=21959)$ in FP clinics in the same counties. GC positivity in CHCs was $1.3 \%(n=594)$ and $0.2 \% \quad(n=2296)$ among females aged $15-19$ and 20-25 years, respectively, compared with $1.0 \%(n=6548)$ and $0.3 \%(n=13334)$ in FP clinics (Abstract P5-S7.11 table 1). Over 99\% of tests in CHCs were performed using highly sensitive nucleic acid amplification tests (NAATs), vs $55 \%$ of tests performed in FP.

Abstract P5-S7.11 Table 1 Chlamydia and gonorrhoea testing and positivity among females aged $15-25$ years attending community health centers and family planning clinics for non-prenatal visits, CY2009, Region II Infertility Prevention Project, USA

\begin{tabular}{lllllll}
\hline \multirow{2}{*}{ Test type } & $\begin{array}{l}\text { Age Group } \\
\text { (Years) }\end{array}$ & \multicolumn{2}{c}{ Community health centers } & & \multicolumn{2}{c}{ Family planning clinics } \\
\cline { 3 - 4 } \cline { 6 - 7 } Chlamydia & $15-19$ & 640 & $11.4 \%$ & & 10946 & $8.5 \%$ \\
& $20-25$ & 2463 & $5.7 \%$ & & 21959 & $4.6 \%$ \\
& Total & 3103 & $6.9 \%$ & & 32905 & $5.9 \%$ \\
Gonorrhoea & $15-19$ & 594 & $1.3 \%$ & & 6548 & $1.0 \%$ \\
& $20-25$ & 2296 & $0.2 \%$ & & 13334 & $0.3 \%$ \\
& Total & 2890 & $0.4 \%$ & & 19882 & $0.6 \%$ \\
\hline
\end{tabular}

Conclusion The burden of chlamydia and gonorrhoea among females aged $15-25$ years attending $\mathrm{CHCs}$ is comparable to that observed in FP clinics, and highest among teens. As state and local health departments face mounting budget deficits and impending cuts to public health infrastructure-including cuts to the delivery of direct clinical services, CHCs may play an increasingly integral role in providing screening to the most at risk populations. CHCs are required to report to HRSA (the federal agency that funds the $\mathrm{CHC}$ program) on their performance using the measures defined in the Uniform Data System (UDS); however, the UDS does not currently include a measure for the proportion of clients screened for CT/GC. State and local health departments should consider opportunities to partner with CHCs in high morbidity areas to ensure and expand access to CT/GC screening and treatment for at risk populations, and leverage existing infrastructure to incorporate $\mathrm{CHCs}$ into ongoing prevalence monitoring efforts.

\section{P5-S7.12 STD TESTING IN EMERGENCY DEPARTMENT: A NOVEL METHOD TO PROVIDE TEST RESULTS}

doi:10.1136/sextrans-2011-050108.607

${ }^{1} \mathrm{~J}$ Arno, ${ }^{2} \mathrm{~F}$ Messina, ${ }^{3} \mathrm{~A}$ Perkins, ${ }^{2} \mathrm{~A}$ Allen. ${ }^{1}$ Indiana University School of Medicine \& Marion Couny Public Health Department, Indianapolis, USA; ${ }^{2}$ Indiana University School of Medicine, Indianapolis, USA; ${ }^{3}$ Anthony Perkins Statistical Consulting, Brownsburg, USA

Background Realising the potential of broad based STD testing depends on treatment of those with positive results. Because emergency department (ED) physicians expressed reluctance to test for STD's because they had no mechanism for giving test results, we devised a system to provide results to patients tested for STD's at the county's public hospital by calling Bell Flower, the health department's STD program, to determine whether patients tested for STD's in the ED would call for their results.

Methods An electronically generated individually modified referral note with instructions for calling Bell Flower for STD test results was given to all patients tested for STD's including gonorrhoea (GC), Chlamydia (CT) or syphilis, in the Wishard Hospital Emergency Department. The Bell Flower results clerk was given access to the hospital's electronic medical record system containing laboratory results. The clerk's access to a specific patient's results was recorded electronically by the system. Patient records accessed by 